\title{
Benign Thyroid Disease causing RLN Palsy
}

\author{
${ }^{1}$ Deependra Narayan Singh, ${ }^{2}$ Amit Agarwal, ${ }^{3}$ Sushil Gupta, ${ }^{4}$ Manoj Jain \\ ${ }^{1}$ Senior Resident, Department of Endocrine Surgery, SGPGIMS, Lucknow, Uttar Pradesh, India \\ ${ }^{2}$ Additional Professor, Department of Endocrine Surgery, SGPGIMS, Lucknow, Uttar Pradesh, India \\ ${ }^{3}$ Additional Professor, Department of Endocrinology, SGPGIMS, Lucknow, Uttar Pradesh, India \\ ${ }^{4}$ Additional Professor, Department of Pathology, SGPGIMS, Lucknow, Uttar Pradesh, India
}

Correspondence: Amit Agarwal, Additional Professor, Department of Endocrine Surgery, SGPGIMS, Lucknow-14, Uttar Pradesh India, Phone: 91(522) 2494393, Fax: 91(522)-2668017, 91(522)-2668078, e-mail: amitsgpgi@ rediffmail.com

\section{ABSTRACT}

Patients with goiter who have associated RLN palsy and/or hoarseness of voice are usually thought to have a malignant goiter, which has directly or indirectly involved the RLN. However, cases of vocal cord palsy in the setting of benign thyroid disease, though rare has been reported in literature. We present five cases of vocal cord palsy associated with benign thyroid disease and discuss the mechanisms of the vocal cord paralysis and also highlight the impact of early surgery on voice recovery.

Keywords: Benign thyroid disease, RLN palsy.

\section{INTRODUCTION}

Patients with goiter who have associated RLN palsy and/or hoarseness of voice are usually thought to have a malignant goiter, which has directly or indirectly (by way of infiltrative lymph nodes) involved the RLN. However, cases of vocal cord palsy in the setting of benign thyroid disease, though rare has been reported in literature. We present five cases of vocal cord palsy associated with benign thyroid disease and discuss the mechanisms of the vocal cord paralysis and also highlight the impact of early surgery on voice recovery.

\section{PATIENTS AND METHODS}

The case records of single surgeon (AA) were reviewed. During 1997 to 2010, 700 patients of benign goiter were operated. All patients were worked-up according to a standard protocol, which included FNAC, USG, TFT, IDL, X-ray soft tissue neck and routine hematology and chemistry. Five patients $(0.71 \%)$ of vocal cord palsy were found to be associated with benign thyroid disease. Vocal cord palsy was documented by indirect as well as flexible laryngoscopy. Postoperative recovery of vocal cord movement was analyzed by either indirect or flexible laryngoscopy performed at 1, 3 and 6 months after operation.

\section{CASE REPORTS}

Case 1

A 49-year-old lady gynecologist was seen with complaints of hoarseness of voice following a bout of cold for one year. She was recently detected diabetic and was controlled on oral hypoglycemic agents. She revealed past history of pulmonary tuberculosis at the age of 29 years and had received full course of antitubercular drugs. On examination of the neck, there was a right lobe solitary nodule of size $3 \times 3 \mathrm{~cm}$ with evidence of retrosternal extension and absence of palpable cervical lymphadenopathy. One and half month back she was evaluated by flexible laryngoscopy, which revealed right-sided vocal cord palsy with no endolaryngeal growth with presence of phonatory gap (Fig. 1). She was clinically and biochemically euthyroid. On routine evaluation by high resolution neck ultrasonography a posteriorly placed right side solitary thyroid nodule of size $33 \times 38 \mathrm{~mm}$ with increased vascularity at periphery with no microcalcification and a normal opposite lobe and isthmus was found. CECT of neck showed presence of a heterogeneous mass measuring $5 \times 4.3 \mathrm{~cm}$ seen in the right lobe of thyroid gland extending into retrosternal region and causing mild mass effect over the trachea (Figs 2A and B). Left lobe of thyroid gland appeared normal. A fibrocalcific lesion was seen in the left upper lobe of lung. Ultrasound-guided FNAC done from right

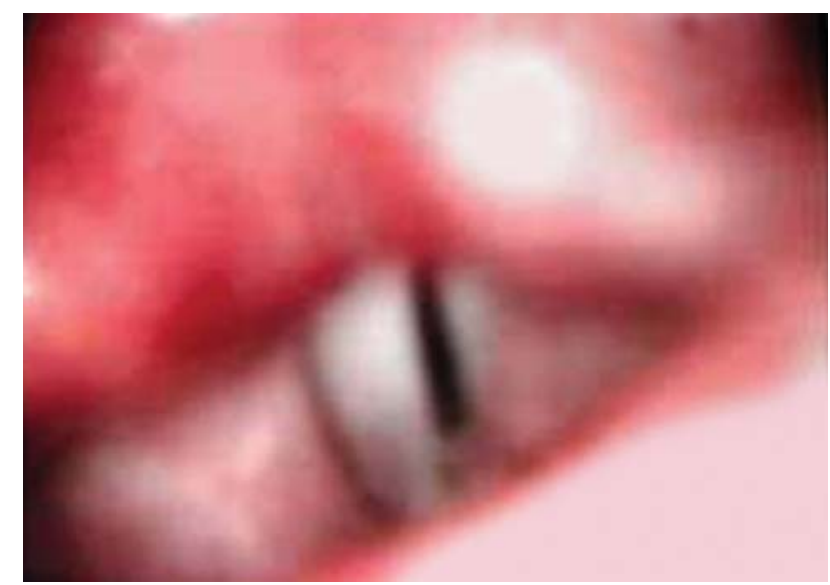

Fig.1: Flexible fiber-optic laryngoscopy of case 1, showing right side vocal cord palsy 
thyroid nodule was consistent with colloid nodule. She underwent right side hemithyroidectomy under general anesthesia. A large right thyroid lobe nodule arising from posterior aspect measuring $7 \times 7.2 \times 4.0 \mathrm{~cm}$, going into retrosternal space with no gross adhesion to surrounding structures was noted intraoperatively. The thyroid gland could be delivered via cervical route. Frozen section showed no evidence of malignancy. She had uneventful postoperative recovery. The histopathology confirmed colloid nodule.

\section{Case 2}

A 57-year-old man noticed recent onset of sudden aphonia of 15 days duration. He also noticed recent appearance of a neck swelling in last 10 days. However, it was not associated with any difficulty in breathing or swallowing. He was diabetic and hypertensive for 8 years, well controlled on oral hypoglycemic and antihypertensive agents. On examination, a left side solitary thyroid nodule of size $4.5 \times 5 \mathrm{~cm}$ with retrosternal extension was present. Thyroid gland had restricted mobility in both vertical and transverse planes. There was no palpable cervical lymph node. Thyroid function tests revealed subclinical hyperthyroidism. Flexible laryngoscopy showed left-sided vocal cord palsy along with left side vocal cord thickening. CECT neck showed left lobe thyroid nodule with retrosternal extension with no evidence of cervical lymphadenopathy. He underwent FNAC from thyroid left lobe showing degenerated and lysed red blood cells and inflammatory cells. No definite malignant cells were seen in smear. He was planned for left hemithyroidectomy but because of the presence of gross adhesions of the left thyroid lobe with strap muscles total thyroidectomy was performed keeping the possibility of malignancy in mind. During surgery, a large size left lobe nodule of $9 \times 8 \mathrm{~cm}$ with retrosternal extension was found. Cut section showed two nodules, largest $6 \times 5 \mathrm{~cm}$ size present in lower pole with lot of hemorrhagic and necrotic material. Right lobe also revealed five small nodules, largest being $2 \times 2 \mathrm{~cm}$. Both superior and recurrent laryngeal nerves on both sides identified and preserved. Postoperatively there was smooth recovery except for transient hypocalcemia. Histopathology revealed benign multinodular goiter with degenerative changes and inflammation.

\section{Case 3}

A 55-year-old male noticed sudden onset of hoarseness of voice of 25 days duration, and there was no improvement with time. He did not notice any swelling in the neck. No features suggestive of hyper- or hypothyroidism were present. He had no difficulty in breathing or swallowing. On examination of the neck, a left-sided solitary thyroid nodule with retrosternal extension was present. There was no palpable cervical lymphadenopathy noted in neck. He had severe ankylosing spondylosis with severe restriction of neck movements. He had undergone indirect laryngoscopy followed by flexible laryngoscopy, both of which revealed left-sided vocal cord palsy. USG neck and CT scan neck and upper thorax showed left thyroid nodule $6 \times 4 \mathrm{~cm}$ with retrosternal extension with normal opposite lobe and isthmus. Ultrasound-guided FNAC from left thyroid nodule showed fair number of cyst macrophages on a hemorrhagic background with no evidence of malignancy. Left hemithyroidectomy was done in neutral position of neck. The retrosternal part of left lobe was via cervical route. Left recurrent laryngeal nerve was found to be stretched out (Fig. 3) and compressed by left thyroid lobe. The gross specimen measured $7 \times 6 \times 4 \mathrm{~cm}$ with weight of $60 \mathrm{gm}$; cut section showed brown color fluid filled cystic area in lower pole of left thyroid lobe. Postoperative course was uneventful. Histopathology revealed colloid nodule with cystic degeneration.

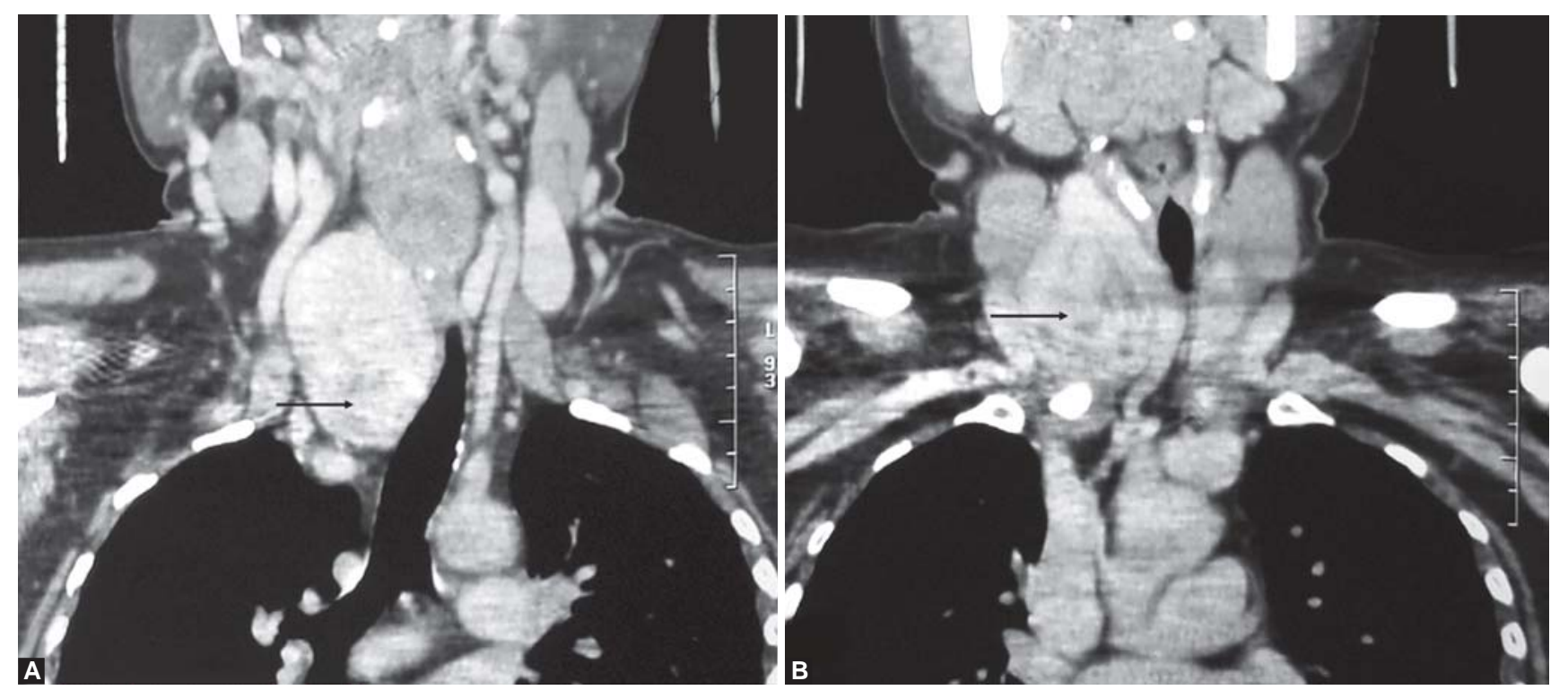

Figs 2A and B: CECT neck and upper chest of case 1, showing posteriorly placed thyroid nodule with retrosternal extension (Black arrow ) 


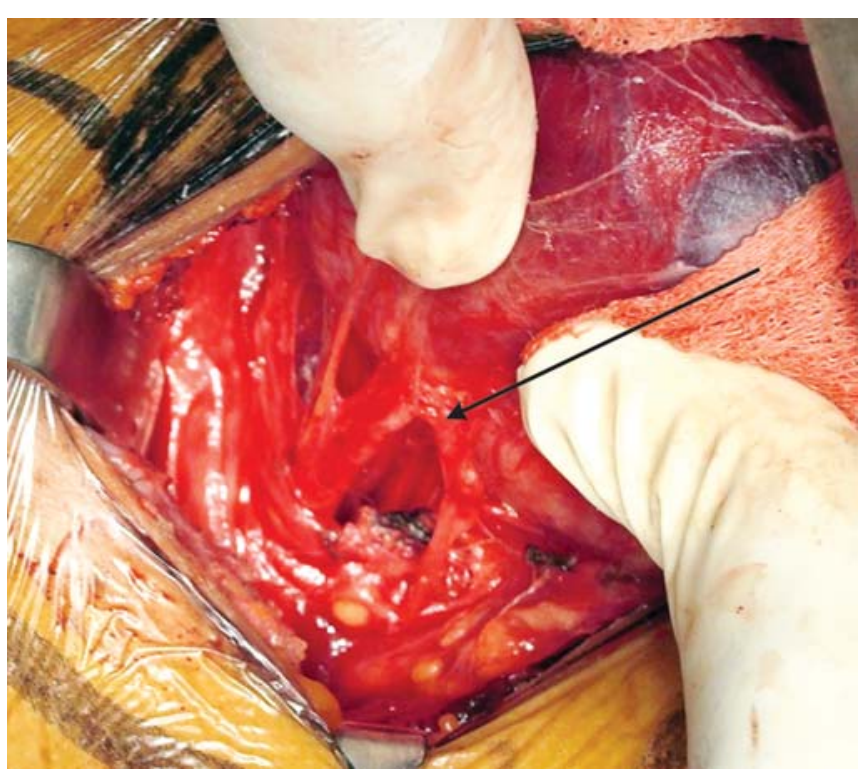

Fig. 3: Stretched out left RLN (black arrow)

\section{Case 4}

A 78-year-old elderly man presented with recent onset hoarseness of voice with anterior neck swelling. No features of breathing or swallowing difficulty were present. He was clinically and biochemically euthyroid. On neck examination, a right-sided solitary thyroid nodule of size approximately $8 \times 4 \mathrm{~cm}$ with retrosternal extension was noted. There were no lymph nodes palpable in neck. On indirect laryngoscopy, right-sided vocal cord palsy was present. FNAC from right thyroid nodule suggested colloid nodule. USG neck showed right lobe thyroid nodule of $8.6 \times 5.0 \mathrm{~cm}$ with no cervical lymphadenopathy and normal size, and echogenicity of left lobe and isthmus. He underwent right hemithyroidectomy. Intraoperatively, the right side recurrent laryngeal nerve was found to be stretched by enlarged right thyroid lobe but there was no gross adhesion or invasion to adjacent structures. Histopathology revealed nodular colloid goiter with few areas of necrosis and hemorrhages.

\section{Case 5}

A 55-year-old elderly lady noticed sudden onset of hoarseness of voice of one month duration. She also noticed recent appearance of neck swelling in last 2 months. There was no feature of breathing and swallowing difficulty as well as no features suggestive of hyper- or hypothyroidism. On examination of neck, a left side solitary thyroid nodule of $4 \times 5 \mathrm{~cm}$ was present with nonpalpable right thyroid lobe. There was no retrosternal extension or any palpable cervical lymphadenopathy noted in neck. She underwent flexible laryngoscopy, which revealed left-sided fixed vocal cord. USG neck and CT scan neck and upper thorax showed left thyroid nodule $4 \times 3 \mathrm{~cm}$ with normal opposite lobe and isthmus. FNAC smear from left thyroid nodule shows cellular colloid nodule with no evidence of malignancy. She underwent left side hemithyroidectomy under general anesthesia. Large size left thyroid lobe nodule arising from posterior aspect with a size of $4.0 \times 4.0 \mathrm{~cm}$ with no gross adhesion to surrounding structure was noted intraoperatively. Frozen section biopsy did not show any evidence of malignancy. She had uneventful postoperative recovery. Histopathology confirmed left lobe multinodular goiter with granulomatous inflammation. However, Ziehl Neelsen stain was negative for Acid Fast Bacilli.

\section{RESULTS}

There were five patients with benign thyroid disease with unilateral vocal cord paralysis. There was no case of bilateral palsy. All patients presented with the chief complaints of recent onset aphonia or hoarseness of voice. Two had solitary thyroid nodule and three had multinodular goiter. All the patients with solitary thyroid nodule had ipsilateral vocal cord palsy. There was no case of contralateral palsy. All patients were clinically and biochemically euthyroid. Table 1 illustrates the operative findings and pathology of the five cases. Postoperatively, all the patients showed significant and sustained improvement in voice and vocal cord mobility. A sequential flexible laryngoscopic study was available in three patients and all of these showed full movements of the vocal cords.

\section{DISCUSSION}

Thyroid enlargement associated with or presenting with vocal cord palsy heightens the suspicion of thyroid malignancy. However, the vocal cord palsy may also be caused by benign thyroid disease. The true incidence of the association of vocal cord palsy with benign thyroid enlargement is unknown because as many as 30 to $50 \%$ of patients with unilateral RLN palsy may be asymptomatic, and thus may not seek medical attention. ${ }^{1,2}$ In the series by RJM Julian et al, ${ }^{3}$ the incidence of preoperative VC palsy was $0.96 \%$ (22 out of 2321 operated patients of benign thyroid disease). In their series, 17 out of the 19 patients with sufficient postoperative laryngoscopic followup, had recovery of the RLN palsy, hence the VC palsy can be attributed to benign thyroid pathology. Previously, Reuger et $\mathrm{al}^{4}$ reviewed their series of patients undergoing thyroid surgery for benign enlargement from 1939 to 1969 and reported an incidence of spontaneous, unilateral RLN palsy of $0.7 \%$. HollAllen reported a preoperative incidence of VC palsy of $0.69 \%$ (8 out of 1156 patients of benign thyroid disease). ${ }^{5}$

Various mechanisms have been suggested for the VC palsy associated with benign goiter. These include compression (of the RLN and/or its blood supply), stretching of the RLN (by the large goiter or by the retrosternal component), inflammation or edema of RLN (as in thyroiditis). Three of our cases showed stretching of the RLN by the retrosternal component of the solitary thyroid nodule. Also, sometimes the position of the thyroid nodule may be more important than the absolute size of the goiter as happened in case no 1 . In this case, the thyroid enlargement was moderate but because of the posterior location of the nodule, the nerve could be compressed early on. HollAllen felt that stretching of RLN was only responsible in cases 


\begin{tabular}{|c|c|c|c|c|c|c|}
\hline \multicolumn{2}{|c|}{$\begin{array}{c}\text { S.No. Symptomsx } \\
\text { duration }\end{array}$} & \multirow{2}{*}{$\begin{array}{c}\text { Position of } \\
\text { paralyzed VC } \\
\text { Right paramedian }\end{array}$} & \multirow{2}{*}{\begin{tabular}{l}
\multicolumn{1}{c}{$\begin{array}{c}\text { Operative } \\
\text { findings }\end{array}$} \\
Large $(7 \times 7 \mathrm{~cm})$ \\
posteriorly \\
placed nodule with \\
retrosternal extension
\end{tabular}} & \multirow{2}{*}{$\begin{array}{c}\text { Operative } \\
\text { procedure }\end{array}$} & \multirow{2}{*}{$\begin{array}{c}\text { Pathology } \\
\text { Colloid nodule }\end{array}$} & \multirow{2}{*}{$\begin{array}{l}\text { Follow-up } \\
\text { Improved voice with } \\
\text { improved VC mobility }\end{array}$} \\
\hline 1 & $\begin{array}{l}\text { Hoarseness } \times \\
2 \text { months }\end{array}$ & & & & & \\
\hline 2 & $\begin{array}{l}\text { Aphonia } \times \\
15 \text { days }\end{array}$ & Left paramedian & $\begin{array}{l}\text { Large }(9 \times 8 \mathrm{~cm}) \\
\text { nodule with retrosternal } \\
\text { extension with adherence } \\
\text { to strap muscles }\end{array}$ & Total thyroidectomy & $\begin{array}{l}\text { Multinodular goiter } \\
\text { with degenerative } \\
\text { changes, suppurative } \\
\text { inflammation and } \\
\text { fibrosis }\end{array}$ & $\begin{array}{l}\text { Improved voice with } \\
\text { improved VC mobility }\end{array}$ \\
\hline 3 & $\begin{array}{l}\text { Hoarseness } \times \\
25 \text { days }\end{array}$ & Left paramedian & $\begin{array}{l}7 \times 6 \mathrm{~cm} \text { nodule with } \\
\text { retrosternal extension } \\
\text { stretching the RLN }\end{array}$ & Hemithyroidectomy & $\begin{array}{l}\text { Colloid nodule with } \\
\text { cystic degeneration }\end{array}$ & $\begin{array}{l}\text { Complete voice } \\
\text { recovery with full VC } \\
\text { mobility }\end{array}$ \\
\hline 5 & $\begin{array}{l}\text { Hoarseness } \times \\
1 \text { month }\end{array}$ & Left paramedian & $\begin{array}{l}4 \times 4 \mathrm{~cm} \text { with } \\
\text { retrosternal extension }\end{array}$ & Hemithyroidectomy & $\begin{array}{l}\text { Multinodular goiter } \\
\text { with granulomatous } \\
\text { inflammation }\end{array}$ & $\begin{array}{l}\text { Improved voice with } \\
\text { improved VC } \\
\text { mobility }\end{array}$ \\
\hline
\end{tabular}

of retrosternal goiter. ${ }^{5}$ In the series by RJM Julian, ${ }^{3}$ the cause of RLN palsy was attributed to direct compression (2 cases) and stretching (12 cases-11 had retrosternal extension, and in one case, RLN was clearly stretched by a cyst expanding into the mediastinum).

The patients who have VC palsy and are symptomatic, usually experience symptoms like hoarseness or aphonia of relatively short duration and perhaps this is why most series report almost full recovery after thyroidectomy. In the series by CCL Maria, out of eight patients of VC palsy, six patients (75\%) who had postoperative and subsequent laryngoscopic examination showed improvement in voice and/or improved VC mobility. ${ }^{6}$ Similarly, in the series by RJM Julian, ${ }^{3}$ out of 19 patients who had sufficient follow-up available, 17 showed good recovery of voice (89\%). In our series of 1578 patients with benign thyroid disease, five patients $(0.31 \%)$ had vocal cord palsy. In conclusion, in patients with goiter associated with VC palsy, the paralysis is not always due to thyroid malignancy. The cause of palsy could be the retrosternal extension of the benign goiter or direct compression of the RLN by the posteriorly placed nodule. Early surgery should be contemplated as the chances of full recovery of voice function are very high. The surgeon should expect a stretched out RLN during surgery and should make every effort to dissect and carefully preserve the RLN.

\section{REFERENCES}

1. Cunning DS. Unilateral vocal cord paralysis. Ann Otol Rhinol Laryngol 1955;64:487-93.

2. Huppler EG, Schmidt HW, Devine KD, Page RP. Ultimate outcome of patients with vocal cord paralysis of undetermined cause. Am Rev Tuberc Pulm Dis 1956;73:52-60.

3. Rowe-Jones JM, Rosswick RP, Leighton SE. Benign thyroid disease and vocal cord palsy. Ann R Coll Surg Engl July 1993;75(4):241-44.

4. Rueger RG. Benign disease of the thyroid gland and vocal cord paralysis. Laryngoscope 1974;84:897-907.

5. Holl-Allen RTJ. Laryngeal nerve paralysis and benign thyroid disease. Arch Otolaryngol 1967;85:121-23.

6. Collazo-Clavell ML, Gharib H, Maragos NE. Relationship between vocal cord paralysis and benign thyroid disease. Head and Neck Jan-Feb 1995;17(1):24-30. 